\title{
Combining cellulose nanofibrils and galactoglucomannans for enhanced stabilization of future food emulsions
}

\author{
Ragnhild Aaen • Mari Lehtonen · Kirsi S. Mikkonen • Kristin Syverud $\mathbb{D}$
}

Received: 26 March 2021 / Accepted: 16 September 2021 / Published online: 23 September 2021

(C) The Author(s) 2021

\begin{abstract}
The use of wood-derived cellulose nanofibrils (CNFs) or galactoglucomannans (GGM) for emulsion stabilization may be a way to obtain new environmentally friendly emulsifiers. Both have previously been shown to act as emulsifiers, offering physical, and in the case of GGM, oxidative stability to the emulsions. Oil-in-water emulsions were prepared using highly charged (1352 $\pm 5 \mu \mathrm{mol} / \mathrm{g}) \mathrm{CNFs}$ prepared by TEMPO-mediated oxidation, or a coarser commercial CNF, less charged $(\approx 70 \mu \mathrm{mol} / \mathrm{g}$ ) quality (Exilva forte), and the physical emulsion stability was evaluated by use of droplet size distributions,
\end{abstract}

Supplementary Information The online version contains supplementary material available at https://doi.org/10.1007/ s10570-021-04213-x.

R. Aaen $\cdot$ K. Syverud $(\bowtie)$

Ugelstad Laboratory, Department of Chemical

Engineering, Norwegian University of Science and

Technology, N- 7491 Trondheim, Norway

e-mail: kristin.syverud@rise-pfi.no

\section{Lehtonen · K. S. Mikkonen}

Department of Food and Nutrition, University of Helsinki,

P.O. Box 66, 00014 Helsinki, Finland

\section{K. S. Mikkonen}

Helsinki Institute of Sustainability Science (HELSUS), University of Helsinki, P.O. Box 65, 00014 Helsinki,

Finland

K. Syverud

RISE PFI, N-7491 Trondheim, Norway micrographs and visual appearance. The highly charged, finely fibrillated CNFs stabilized the emulsions more effectively than the coarser, lower charged CNFs, probably due to higher electrostatic repulsions between the fibrils, and a higher surface coverage of the oil droplets due to thinner fibrils. At a constant $\mathrm{CNF} /$ oil ratio, the lowest $\mathrm{CNF}$ and oil concentration of 0.01 wt $\% \mathrm{CNFs}$ and 5 wt $\%$ oil gave the most stable emulsion, with good stability toward coalescence, but not towards creaming. GGM $(0.5$ or $1.0 \mathrm{wt}$ $\%$ ) stabilized emulsions (5 wt \% oil) showed no creaming behavior, but a clear bimodal distribution with some destabilization over the storage time of 1 month. Combinations of CNFs and GGM for stabilization of emulsions with 5 wt $\%$ oil, provided good stability towards creaming and a slower emulsion destabilization than for GGM alone. GGM could also improve the stability towards oxidation by delaying the initiation of lipid oxidation. Use of CNFs and combinations of GGM and CNFs can thus be away to obtain stable emulsions, such as mayonnaise and beverage emulsions.

Keywords Nanocellulose Cellulose nanofibrils $(\mathrm{CNFs}) \cdot$ Galactoglucomannans $(\mathrm{GGM}) \cdot \mathrm{o} / \mathrm{w}$ emulsions $\cdot$ Stabilizers 


\section{Introduction}

Stabilization of emulsions with wood-derived stabilizers such as variations of cellulose and hemicelluloses has been the focus of several research papers in recent years. These studies include work on cellulose nanocrystals (CNCs), CNFs and GGM, and show differences in stabilization mechanisms between the different stabilizers (Capron and Cathala 2013; Fujisawa et al. 2017; Gestranius et al. 2017; Mikkonen et al. 2009; Xhanari et al. 2011a,b). As emulsions are found in a wide range of products from cosmetics to food products, emulsion stabilizers have vast opportunities in many application areas. Stabilizers can either adsorb to the $\mathrm{o} / \mathrm{w}$ interface of the droplets and prevent coalescence, or act as viscosifiers or gelling agents in the continuous phase, slowing down gravitational emulsion destabilization (Mcclements 2007). Emulsion stabilizers encompass groups such as proteins, polysaccharides, phospholipids, small molecule surfactants or solid particles (Binks 2002; Mcclements 2007; Pickering 1907b; Whitehurst 2004). Surfactants are widely used and effective stabilizers, but can be harmful to the environment (Arslan-Alaton and Erdinc 2006; Gomez et al. 2011; Jardak et al. 2016). This is an important drive to develop new more environmentally friendly emulsion stabilizers. In this sense, woodderived stabilizers are promising candidates.

The most abundant components of wood are cellulose (40-45\%) and hemicelluloses (15-25\%), together composing a group called holocellulose, commonly accounting for $65-70 \%$ of the dry weight of wood (Rowell 2012). In the wood fibres, the cellulose is present as microfibrils, themselves made up of elementary fibrils with diameters of a few nanometers. The term CNFs encompass both the elementary fibrils and the bundles of these (Nechyporchuk et al. 2016). The production of CNFs commonly includes homogenization of wood pulps, often preceded by some kind of pre-treatment of the pulp to facilitate the delamination of the pulp fibres (Klemm et al. 2011). These pre-treatments can e.g. include enzymatic pre-treatment (Pääkkö et al. 2007), carboxymethylation (Wågberg et al. 2008), carboxylation through TEMPO-mediated oxidation (Saito et al. 2006) or periodate-chlorite oxidation (Liimatainen et al. 2012; Tejado et al. 2012), and quaternization (Aulin et al. 2010). Following the pretreatments, the fibrils are mechanically disintegrated to yield CNFs with various morphology and charge densities. Hemicelluloses, in contrast to cellulose, have various chemical composition depending on the type of tree they stem from, and are named after their chemical composition (Rowell 2012). In hardwood, the most common type of hemicelluloses is glucorunoxylan, while GGM is one of the most common types in softwood (Rowell 2012; Sjostrom 1993). The isolation of hemicelluloses is commonly achieved by pressurized hot water extraction (PHWE) (Leppänen et al. 2011; Song et al. 2008) or extraction with aqueous alkali (Aspinall 1959; Gabrielii et al. 2000), followed by filtration and drying.

Spruce galactoglucumannans (GGM) has earlier been shown to stabilize model beverage emulsion systems both against physical destabilization and against lipid oxidation (Lehtonen et al. 2016; Mikkonen et al. 2009; Mikkonen et al. 2016a, b). Phenolic residues from lignin, co-extracted with the hemicelluloses in the PHWE method and partially covalently linked with GGM, are believed to play an important role, both to aid in the adsorption onto the droplet interface and by acting as an antioxidant against lipid oxidation (Carvalho et al. 2020; Lahtinen et al. 2019; Lehtonen et al. 2018). Flocculation of emulsions droplets was observed for dilute emulsions, and contribute to destabilization (Bhattarai et al. 2018; Mikkonen et al. 2016a, b). Depletion flocculation may be an explanation to this phenomenon, as there is much unabsorbed GGM in the continuous phase (Bhattarai et al. 2018). Lignin residues in GGM can contribute a woody taste to solutions and food products, but ethanol precipitation of the GGM largely removes the lignin and reduces the odor, so that it can be masked by other flavors in the food.

In addition to GGM, wood-derived CNFs, with various charge densities and surface modifications, have been used to stabilize emulsions by adsorbing to the droplet interface, forming what is known as Pickering emulsions (Gestranius et al. 2017; Mikulcová et al. 2016; Pickering 1907a; Xhanari et al. 2011a, b). Without surface hydrophobization, the CNFs will stabilize o/w emulsions, and are shown to provide good storage stability up to several months (Aaen et al. 2019a, b; Fujisawa et al. 2016; Gestranius et al. 2017; Lu et al. 2019; Mikulcová et al. 2016). While the emulsions are rather stable against coalescence, they can be prone to flocculation (Cunha et al. 2014; Lu et al. 2019) and creaming (Gestranius et al. 
2017). Creaming is however not observed for all CNF stabilized emulsions (Aaen et al. 2019a, b; Fujisawa et al. 2016). The resistance towards creaming can possibly stem from closer packing of oil droplets at high oil concentration, or by network formation in the continuous phase at higher CNF concentrations, both slowing down the creaming process (Mikulcová et al. 2016).

In this study, the Pickering stabilization of $\mathrm{o} / \mathrm{w}$ emulsions with CNFs have been investigated, and the effect of differences in charge density and fibrillation degree of two types of CNFs have been studied. GGM, with its previously shown ability to provide both physical and oxidative stability to emulsions (Lehtonen et al. 2016; Mikkonen et al. 2016a, b), has been combined with CNFs to investigate if low amounts of CNFs can contribute to an even better physical stability for these emulsions. For these purposes, finely fibrillated, highly charged CNFs prepared by TEMPO-mediated oxidation, more coarsely fibrillated, less charged commercial CNFs (Exilva forte), as well as GGM, and combinations of these have been used to stabilize o/w emulsions. The emulsions were stored in room temperature for 1 month, and the physical stability was evaluated by use of droplet size distributions, micrographs and visual appearance, while the stability towards lipid oxidation was followed by determination of volatile oxidation products.

\section{Materials and methods}

\section{Materials}

The CNFs prepared by TEMPO-mediated oxidation (CNF-T) were prepared from a dissolving pulp (Borregaard, Sarpsborg, Norway), and has previously been described in another paper (Aaen et al. 2019a, b). The pulp was subjected to TEMPO (2,2,6,6-tetramethylpiperidine-1-oxyl-radical)-mediated oxidation as described by Saito and Isogai (2004). Briefly, $110 \mathrm{~g}$ cellulose was suspended in $8.25 \mathrm{~L}$ of deionized water containing $1.375 \mathrm{~g}$ TEMPO and $13.75 \mathrm{~g}$ sodium bromide before sodium hypochlorite was added to start the reaction. The sodium hypochlorite was slowly added, with a total concentration in the reaction mixture of $3.5 \mathrm{mmol} \mathrm{NaClO}$ per gram of cellulose. The $\mathrm{pH}$ was kept at 10.5 during the reaction by adding
$0.5 \mathrm{M}$ sodium hydroxide. When the $\mathrm{pH}$ stayed constant without addition of more sodium hydroxide, the $\mathrm{pH}$ was adjusted to 7 by use of $0.5 \mathrm{M}$ hydrochloric acid. The samples were washed thoroughly with deionized water on a Büchner funnel until the conductivity was less than $5 \mu \mathrm{S} / \mathrm{cm}$. The charge density of the fibres was determined by conductometric titration before homogenization, as described by Saito and Isogai (2006). The pre-treated sample, with a dry content of about $1 \mathrm{wt} \%$ were homogenized using a high pressure homogenizer (Rannie 15 type $12.56 \times$ homogenizer APV, SPX Flow Technology, Silkeborg, Denmark) at two passes, the first at 600 bar, and the second at 1000 bar. The dry content of the final product was measured to be $0.92 \mathrm{wt} \%$. The Exilva forte (2 wt \%) CNFs (CNF-E) were prepared by Borregaard, Sarpsborg, Norway.

The galactoglucomannan (GGM) were obtained from spruce saw meal (Herralan Saha, Herrala, Finland) by use of the PHWE method described by Kilpelainen et al. (2014). A total of $97 \mathrm{~kg}$ (44 kg dry weight) of milled spruce saw meal was extracted at $170{ }^{\circ} \mathrm{C}$ for $70 \mathrm{~min}$ at a flow-rate of $20 \mathrm{~kg} \mathrm{~min}^{-1}$, and the extract $\mathrm{pH}$ adjusted to about 7 with sodium hydroxide before ultrafiltration with tubular modified polyethersulfone membranes (EM006), as described by Bhattarai et al. (2018). The concentrated GGM obtained from filtration was precipitated with ethanol. GGM concentrate was slowly added to ethanol under mixing and left to precipitate overnight. The precipitated polysaccharide slurry was transferred to a filter bag (Eaton NMO25-P01R-50 S, Hyxo Oy, Finland) for removal of excess ethanol, and filtered through a Buchner funnel using a pore 2 cellulose filter (Whatman). After drying in a vacuum oven at $40{ }^{\circ} \mathrm{C}$ for 2 days, the purified sample consisted mainly of polysaccharides, mostly GGM.

Rapeseed oil (Rema 1000, Norway) was purchased from a local store, and used as such. The oil had a density of $0.913 \mathrm{~g} / \mathrm{cm}^{3}$ at $20{ }^{\circ} \mathrm{C}$. The 2,2,6,6-tetramethylpiperidine-1-oxyl radical was obtained from Sigma-Aldrich Co. (Steinheim, Germany) and used without further purification. Sodium chloride was purchased from Merck (Darmstadt, Germany). The sodium hypochloride was obtained from Carl Roth (Karlsruhe, Germany). The ultrapure water used in the experiments was from a Milli-Q filtration system (Merck Millipore, Darmstadt, Germany). 


\section{Characterization of CNFs}

The charge density was determined by conductometric titration. Images of the CNF samples were acquired by atomic force microscopy (AFM), with a Bruker Multimode V AFM with a Nanoscope V Controller (Veeco Instruments Inc., Santa Barbara, CA, USA). The instrument was located at the NorLab facility NTNU Nanolab in Trondheim. A drop of aqueous CNF dispersion with concentration $0.01 \mathrm{wt} \%$ was placed on freshly cleaved $10 \mathrm{~mm}$ mica (Agar Scientific Ltd. Essex, UK) and dried using compressed $\mathrm{N}_{2}$ gas. The films were mounted with double-sided tape on mica before imaging. The operation mode used was quantitative nanomechanical mapping (QNM) with automated settings. The Scan Asyst mode in air at ambient temperature was used to acquire the images, with a nominal spring constant of $0.4 \mathrm{Nm}^{-1}$ and resonance frequenzy $70 \mathrm{kHz}$. Silicon nitride AFM tips, SA-air, were provided by Bruker AFM Probes (Bruker Nano Inc., Camarillo, CA, USA).

Preparation of CNF and GGM suspensions and emulsions

The CNF suspensions were diluted from $1 \mathrm{wt} \%$ (CNF$\mathrm{T}$ ) and $2 \mathrm{wt} \%$ (CNF-E) with MQ water by the use of an Ultra-Turrax at $20000 \mathrm{rpm}$ for $5 \mathrm{~min}$, followed by three passes through a M-110Y Microfluidizer ${ }^{\circledR}$ (Microfluidics, Westwood, USA) at 750 bar to obtain evenly dispersed samples. The Microfluidizer was fitted with $75 \mu \mathrm{m}$ Y-type F20Y and $200 \mu \mathrm{m}$ Z-type $\mathrm{H} 30 \mathrm{Z}$ chambers in series. The GGM, in powder form, was suspended in water by use of magnetic stirring overnight, and then submitted to the same treatment as the CNF suspensions. For mixtures of the two, both GGM and CNFs were stirred with MQ water overnight, followed by the same treatment with the UltraTurrax and the Microfluidizer as described for the CNF suspensions.

The emulsions were prepared by adding the desired amount of rapeseed oil to the CNF/GGM suspensions and mixing them with an Ultra-Turrax at $20000 \mathrm{rpm}$ for 5 min to obtain coarse emulsions. The emulsions were then immediately subjected to three passes through the Microfluidizer at 750 bars to obtain finer emulsions. The emulsions used to study physical stability were transferred into two identical $50 \mathrm{ml}$ sample tubes right after preparation. One of the tubes was photographed and left alone for visual stability studies while the emulsion in the other tube was used to study droplet morphology and the droplet size distribution. All these samples were kept at room temperature during the storage time.

The emulsions used to study oxidative stability were divided into sealed glass vials $(2 \mathrm{~g}$ emulsion per $22 \mathrm{~mL}$ vial) and incubated at $40{ }^{\circ} \mathrm{C}$ for 27 days.

In the first of the emulsion series, only CNFs, at low concentrations, were used for emulsion stabilization, and the amount of both CNFs and rapeseed oil were increased, keeping the ratio between CNFs and oil constant at 0.002 . The composition and sample names of these emulsions are shown in Table 1. In the other series, the emulsions were based on the most stable of the emulsion in the first series, with composition and sample names given in Table 2. The oil content was kept constant at $5 \mathrm{wt} \%$, and CNF-T was used at 0.01 , 0.04 or $0.08 \mathrm{wt} \%$, to observe the effect of increasing the CNFs/oil ratio. The CNFs were used either alone, or with $0.5 \mathrm{wt} \%$ GGM. Emulsions stabilized with 0.5 or 1 wt $\%$ GGM alone, were also prepared for comparison. The GGM concentration of $1 \mathrm{wt} \%$ at $5 \mathrm{wt}$ $\%$ oil is used in previous studies on GGM stabilization (Lehtonen et al. 2016; Mikkonen et al. 2016a, b). The lower concentration of $0.5 \mathrm{wt} \% \mathrm{GGM}$ is used for combinations with CNFs to make it easier to assess the effect of combining the two stabilizers.

In the studies of oxidative stability, the emulsions studied were the ones named 0.08CNF-T(5), 0.5GGM and $0.08 \mathrm{CNF} / \mathrm{GGM}$ from Table 2.

\section{Emulsion stability and droplet size distribution}

The sample tubes containing emulsion were photographed right after emulsion preparation, after one day, one week and one month to study the emulsion stability towards creaming and coalescence over time. The emulsion morphology was characterized using optical microscopy (AxioScope A1, Carl Zeiss Inc, Oberkochen, Germany) at the same time interval as mentioned for the regular photographs. The droplet size distribution of the emulsions was studied by use of laser light diffraction, with a Mastersizer 3000 (Malvern Panalytical, Worcestershire, UK). The sample tube was turned gently upside down 5 times before sample was taken out for analysis with a pipette. The sample was added dropwise to a $400 \mathrm{ml}$ beaker of MQ-water until an obscuration level of 5-10\% was 
Table 1 The composition and sample names of emulsions stabilized with CNF-T or CNF-E with a low and constant CNFs/oil ratio of 0.002

\begin{tabular}{llll}
\hline Sample name & CNF-T [wt\%] & CNF-E [wt\%] & Rapeseed oil [wt\%] \\
\hline $0.01 \mathrm{CNF}-\mathrm{w}$ & 0.01 & - & 5 \\
$0.02 \mathrm{CNF}-\mathrm{T}$ & 0.02 & - & 10 \\
$0.04 \mathrm{CNF}-\mathrm{T}$ & 0.04 & - & 20 \\
$0.06 \mathrm{CNF}-\mathrm{T}$ & 0.06 & - & 30 \\
$0.08 \mathrm{CNF}-\mathrm{T}$ & 0.08 & - & 40 \\
$0.01 \mathrm{CNF}-\mathrm{E}$ & - & 0.01 & 5 \\
$0.02 \mathrm{CNF}-\mathrm{E}$ & - & 0.02 & 10 \\
$0.04 \mathrm{CNF}-\mathrm{E}$ & - & 0.04 & 20 \\
$0.06 \mathrm{CNF}-\mathrm{E}$ & - & 0.06 & 30 \\
$0.08 \mathrm{CNF}-\mathrm{E}$ & - & 0.08 & 40 \\
\hline
\end{tabular}

Table 2 The composition and sample names of emulsions stabilized with CNF-T, GGM or combinations of both, with a constant oil content of 5 wt \%

\begin{tabular}{llll}
\hline Sample name & CNF-T [wt\%] & GGM [wt\%] & Rapeseed oil [wt\%] \\
\hline $0.01 \mathrm{CNF}-\mathrm{T}(5)$ & 0.01 & - & 5 \\
$0.04 \mathrm{CNF}-\mathrm{T}(5)$ & 0.04 & - & 5 \\
$0.08 \mathrm{CNF}-\mathrm{T}(5)$ & 0.08 & - & 5 \\
$0.5 \mathrm{GGM}$ & - & 0.5 & 5 \\
$1 \mathrm{GGM}$ & - & 1.0 & 5 \\
$0.01 \mathrm{CNF} / \mathrm{GGM}$ & 0.01 & 0.5 & 5 \\
$0.04 \mathrm{CNF} / \mathrm{GGM}$ & 0.04 & 0.5 & 5 \\
$0.08 \mathrm{CNF} / \mathrm{GGM}$ & 0.08 & 0.5 & 5 \\
\hline
\end{tabular}

reached. The measurement was run three times for each sample volume, and three more times for a new volume of the sample, giving six measurements for each sample. The droplet size distribution was measured right after preparation, after one day, one week and one month.

Determination of volatile compounds by HSSPME-GC-MS

Oxidative stability of lipids in T-CNF- and GGMstabilized emulsions was evaluated by the formation of volatile lipid oxidation products. Freshly prepared emulsions were divided into sealed glass vials $(2 \mathrm{~g}$ emulsion per $22 \mathrm{~mL}$ vial) and incubated at $40{ }^{\circ} \mathrm{C}$ for 27 days. Sampling was performed on the day of preparation, and on several time points between day 0 and day 27. At each sampling time, three vials were withdrawn for the determination of volatile oxidation products. Formed compounds were determined by head-space solid-phase microextraction in combination to gas chromatographic separation and mass spectrometric detection (HS-SPME-GC-MS) according to Lehtonen et al. (2016). Detection of the compounds was based on total ion chromatogram (TIC) at a m/z range of 40 to 300 , and identification on their mass spectra. Averages and standard deviations of the peak areas were calculated across the three samples. The experiment was performed twice, but as there was a significant time gap between the experiments, peak areas are compared between samples inside one experiment and trends between the two experiments.

\section{Results and discussion}

\section{Characterization of CNFs and GGM}

The charge density of the prepared CNF-T was determined by conductometric titration before homogenization, and found to be $1352 \pm 5 \mu \mathrm{mol} / \mathrm{g}$. The corresponding charge density for the Exilva sample was approximately $70 \mu \mathrm{mol} / \mathrm{g}$.

AFM pictures of the CNF-T and the Exilva are shown in Fig. 1. The pictures clearly show the 


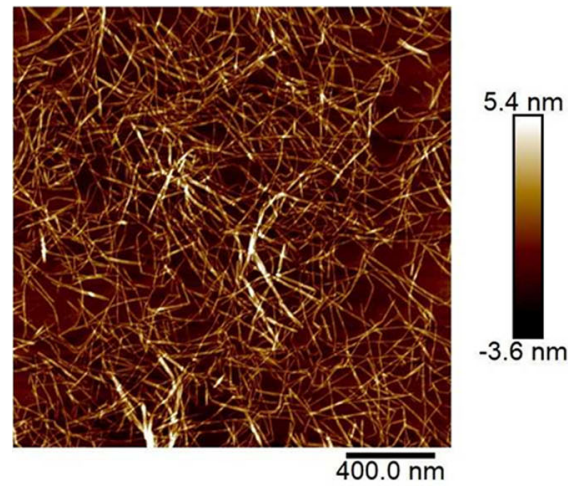

Fig. 1 AFM images of the CNF-T (left), reproduced with permission. Copyright Springer Nature, and Exilva (right) samples, after drying on mica. The pictures show the differences

differences in morphology between the two CNF samples, with a CNF-T being a much more fibrillated material, as expected for such a highly charged CNF quality. Coarser structures are visible for the Exilva sample.

The GGM sample used in this study has previously been characterized in other studies (Bhattarai et al. 2019; Bhattarai et al. 2020). The GGM had an average molecular weight of about $10000 \mathrm{~g} \mathrm{~mol}^{-1}$ (Bhattarai et al. 2019; Mikkonen et al. 2016a; b), but this number should be considered a rough estimate, due to the challenges of high accuracy determination of the molecular weight of polysaccharides. The total polysaccharide content was 86 wt $\%$, and had the composition: $55-60 \%$ mannose, $14-15 \%$ glucose, $10-14 \%$ xylose, $7-10 \%$ galactose, around $3 \%$ galacturonic acid, 2.5-3.5\% methyl-glucuronic acid, and less than $1 \%$ arabinose and rhamnose, based on the dry GGM extract (Bhattarai et al. 2019; Bhattarai et al. 2020; Valoppi et al. 2019). The protein content was 0.8 wt \% (Bhattarai et al. 2020).

\section{Characterization of emulsions stabilized with different qualities of CNFs}

Emulsions where the oil and CNF content were increased while keeping the CNFs/oil ratio constant at 0.002 were prepared. At such low concentrations of CNFs, a network formation in the continuous phase is less likely, and the emulsion stability will most likely be due to adsorption of CNF particles at the oil/water interface. The emulsions were evaluated by use of visual observations, microscopy, and droplet size

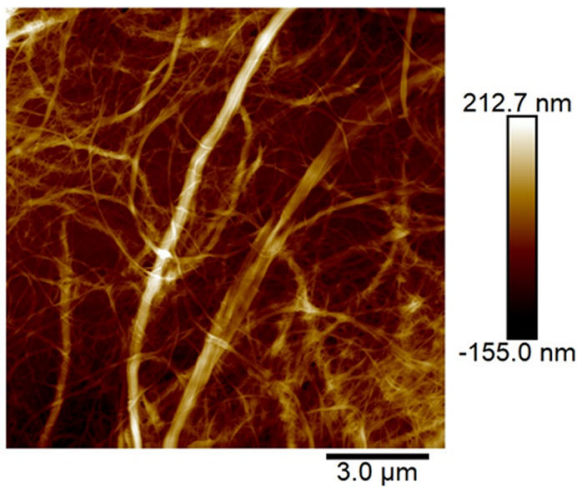

in degree of fibrillation for the two CNF samples. Note the differences between the scale bars

measurements, right after preparation, after 1 day, 1 week and 1 month.

The fresh emulsions were white and opaque, but within the first day of storage, an emulsion concentrated top layer formed, with a gradual compression of the top layer and clearing of the bottom watery layer over the following month of storage. Figure 2 shows all the emulsions after 1 month of storage at room temperature.

After 1 month of storage, all the samples consisted of a top concentrated emulsion layer of white or yellow color, and a clearer bottom layer. A sharper division between these two were observed with increasing CNF and oil concentration, and especially for the emulsions stabilized with CNF-E. For the emulsions 0.06CNF-E and 0.08CNF-E, the color was more yellow than white, which may suggest coalescence of oil droplets, but not to the degree that a clear oil layer is formed. The least marked division between the two layers were seen for the 0.01CNF-Tsample. Gestranius et al. (2017) have previously reported that CNF stabilized emulsion are prone to creaming, for CNFs of varying charge densities. They observed some remaining oil droplets in the phase below the creaming layer for the highly charged TEMPOoxidized CNFs, while not in the emulsions stabilized with CNFs of lower charge density. From the pictures in Fig. 2, a less transparent lower phase is observed for the emulsions stabilized with CNF-T, compared to those stabilized with CNF-E, especially for the higher $\mathrm{CNF}$ and oil concentrations. It is thus reasonable to assume that there are some smaller oil droplets still present in the lower phase of all the CNF-T stabilized 

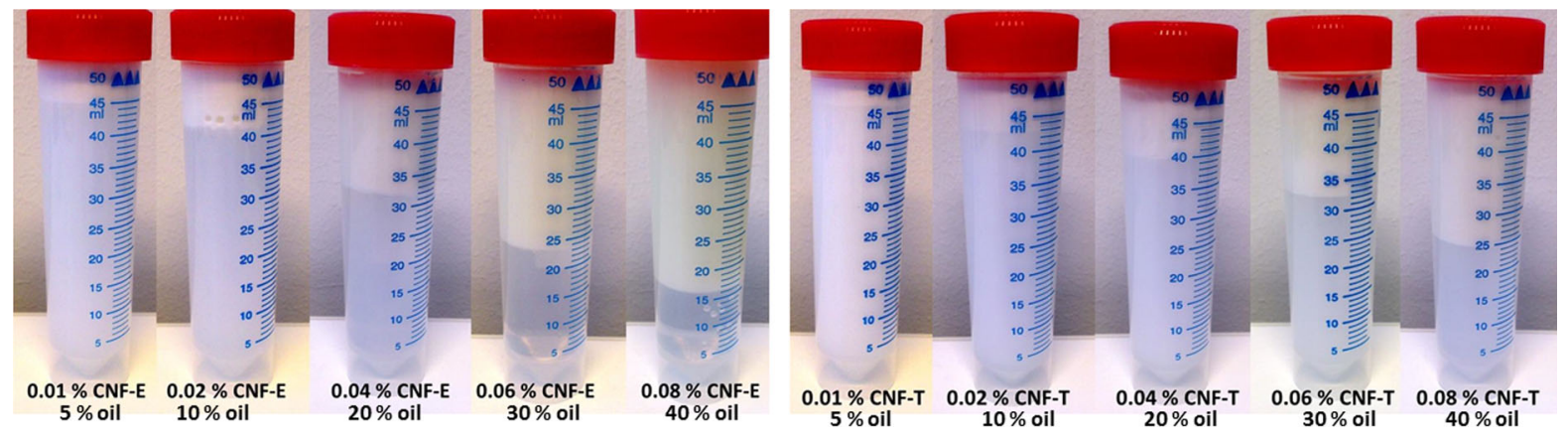

Fig. 2 Pictures of emulsions with increasing oil and CNF content, stabilized with Exilva (CNF-E) or TEMPO-oxidized CNFs (CNF-T), after 1 month of storage at room temperature. The ratio between oil content and CNFs is kept constant between the samples

emulsions, while for the highest oil and CNF-E concentrations, very few or none oil droplets remain in the lower portion of the tubes.

The microscopy images (Fig. 3) show great variations in morphology for the emulsion droplets, depending both on the CNFs used for stabilization, the oil and CNF concentration. Micrographs of the four last samples can be found in Figure S1 in supplementary material. Generally, the smallest droplets were observed for the lowest content of oil and CNFs, with smaller droplets for the emulsions stabilized with CNF-T compared to those stabilized with CNF-E. Clusters of flocculated droplets can be observed, especially for the emulsions containing 0.08CNF-T, and from more dilute emulsions stabilized with CNF-E, from $0.01 \mathrm{wt} \% \mathrm{CNF}-\mathrm{E}$ and $5 \mathrm{wt} \%$ oil. This kind of flocculates have previously been observed by other groups (Cunha et al. 2014; Lu et al. 2019). The flocculation has been attributed to networking between fibrils and droplets, as the longer fibrils can be connected to several oil droplets (Cunha et al. 2014; Lu et al. 2019). As the CNF-E consists of a

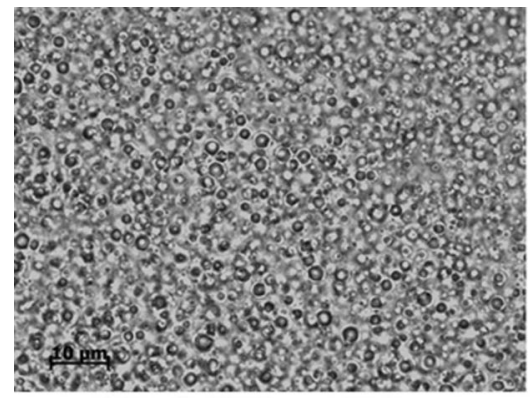

0.01 wt\% CNF-T, 5 wt $\%$ oil

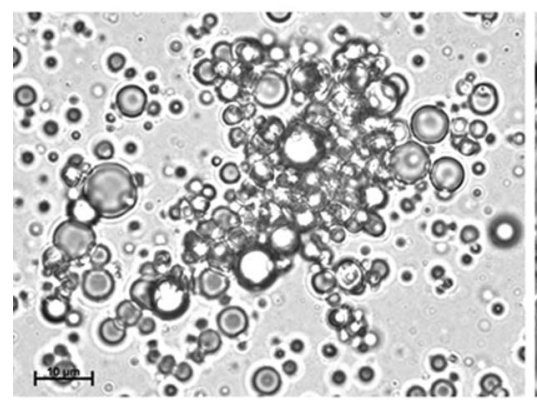

$0.01 w t \%$ CNF-E, $5 w t \%$ oil

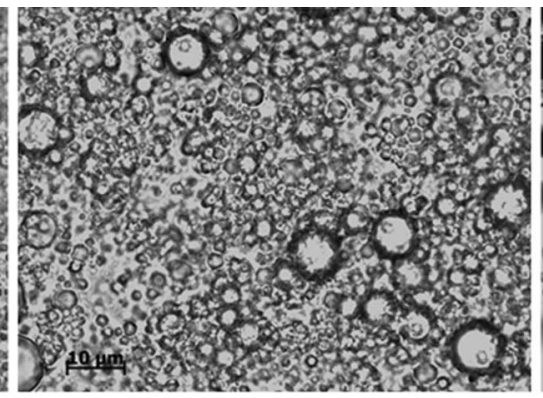

0.04 wt $\%$ CNF-T, 20 wt $\%$ oil

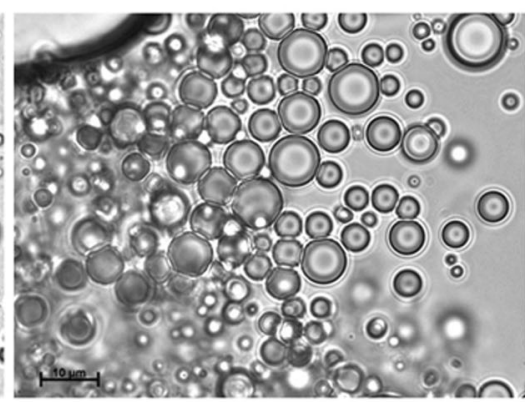

$0.04 w t \%$ CNF-E, 20 wt $\%$ oil

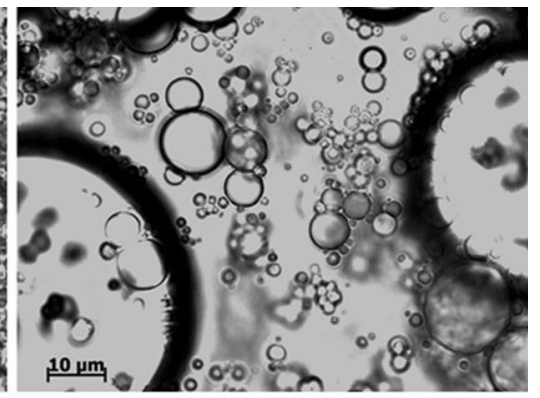

0.08 wt $\%$ CNF-T, 40 wt $\%$ oil

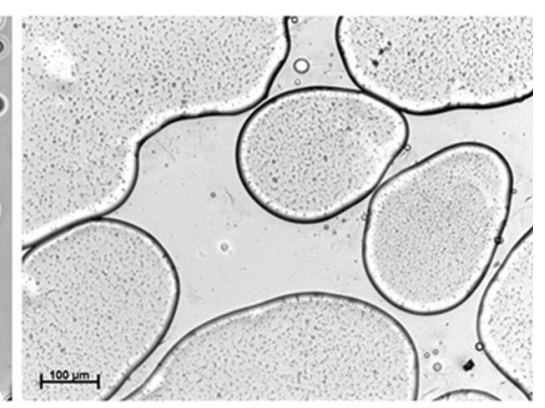

0.08 wt $\%$ CNF-E, 40 wt $\%$ oil
Fig. 3 Optical microscopy of emulsions containing 5, 20 or 40 wt \% rapeseed oil the same day as emulsion preparation, stabilized with TEMPO-oxidized CNFs (CNF-T)-top, and
Exilva CNFs (CNF-E)-bottom. The scale bar is $10 \mu \mathrm{m}$ for all emulsions, except for the $0.08 \%$ CNF-E, $40 \%$ oil, where the scale bar is $100 \mu \mathrm{m}$ 
much coarser material than CNF-T (Fig. 1) this might explain the tendency for droplet clustering at lower CNF-E concentrations compared to CNF-T. According to the Stokes equation, the creaming velocity is proportional to $\mathrm{D}^{2}$, where $\mathrm{D}$ is the average diameter of the emulsion droplets (Walstra 2002). It is thus not surprising to observe a clearer creaming layer for the emulsions with larger droplets, such as the emulsions with higher CNF and oil concentrations. The formation of clusters may also lead to more rapid creaming (Walstra 2002), which can be one of the reasons for the visual differences (Fig. 2) observed between emulsions stabilized with CNF-E and CNF-T.

The volume based droplet size distributions of CNF-T stabilized emulsions, right after preparation and after one month of storage (Fig. 4), confirm large differences between emulsions for increasing CNF and oil content. The surface average droplet size $\left(\mathrm{D}_{3 ; 2}\right)$ and the volume average droplet size $\left(\mathrm{D}_{4 ; 3}\right)$ for the emulsions are shown in Figure S2 in Supplementary material. The smallest droplets are observed for the 0.01CNF-T, emulsion, with a Sauter diameter, $\mathrm{D}_{3 ; 2}$ of $0.313 \pm 0.004 \mu \mathrm{m}$. In comparison, the largest droplets, in the 0.08CNF-T, emulsion, had a Sauter diameter of $9.3 \pm 0.4 \mu \mathrm{m}$. The thinner fibrils of the CNF-T are likely able to cover and stabilize a larger surface area than the thicker CNF-E fibrils at the same concentration, thus allowing for the stabilization of smaller droplets. Small droplet sizes, following from the Stokes equation, gives a slower creaming in the sample than larger droplets, which in turn affects the coalescence, as the creaming leads to more contact between droplets, and thus an increased risk of coalescence. The increase in oil and CNF content leads to a higher viscosity, as more oil/water interfaces are created (Lu et al. 2019). The higher viscosity can in turn lead to poorer emulsification and larger droplets (Winuprasith and Suphantharika 2015), and may be the reason for the very broad distributions observed for the higher oil concentrations. As the CNF-T concentration is very low for all the emulsions, the CNFs are not likely to contribute much to the viscosity compared to the contribution from the dispersed phase. An increasing instability with time is observed for higher oil and CNF concentrations, most likely due to the larger, and thus more unstable droplets, and the increasing polydispersity. The 0.01CNF-T emulsion appears to be rather stable, but with a slight decrease in average droplet size with storage time, possibly due to disappearance of larger droplets through coalescence. Droplet sizes up to about $10 \mu \mathrm{m}$ is not uncommon in food emulsions such as mayonnaise or salad dressings, placing most of the CNF-T stabilized emulsions in a size range acceptable for several food emulsions. For beverage emulsions, smaller droplet sizes, with diameters $200-400 \mathrm{~nm}$ are common, due to the risk of gravitational separation (Piorkowski and McClements 2014).

The emulsions stabilized with CNF-E (Fig. 5), similarly show an increase in droplet sizes with increasing concentrations of oil and CNFs. However, the starting droplet sizes are, as observed in the
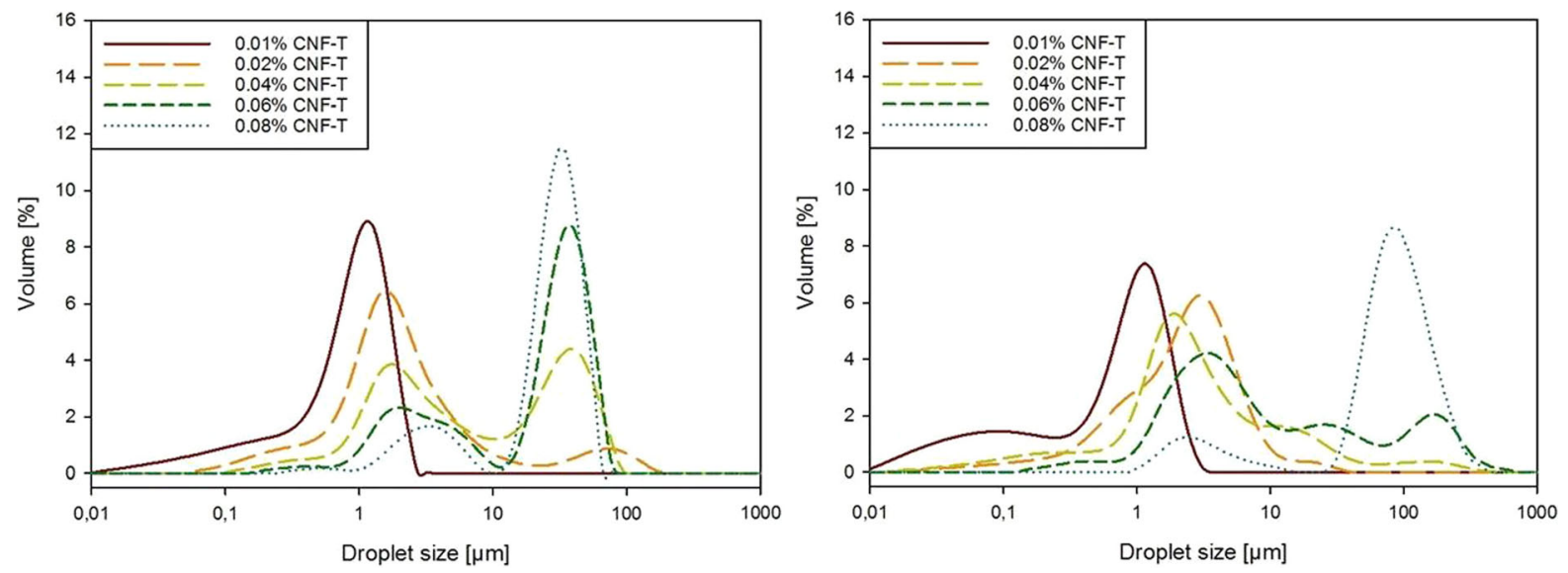

Fig. 4 Volume based droplet size distribution of emulsions stabilized with various concentrations of CNF-T, from a right after preparation and $\mathbf{b}$ after one month of storage at room temperature 

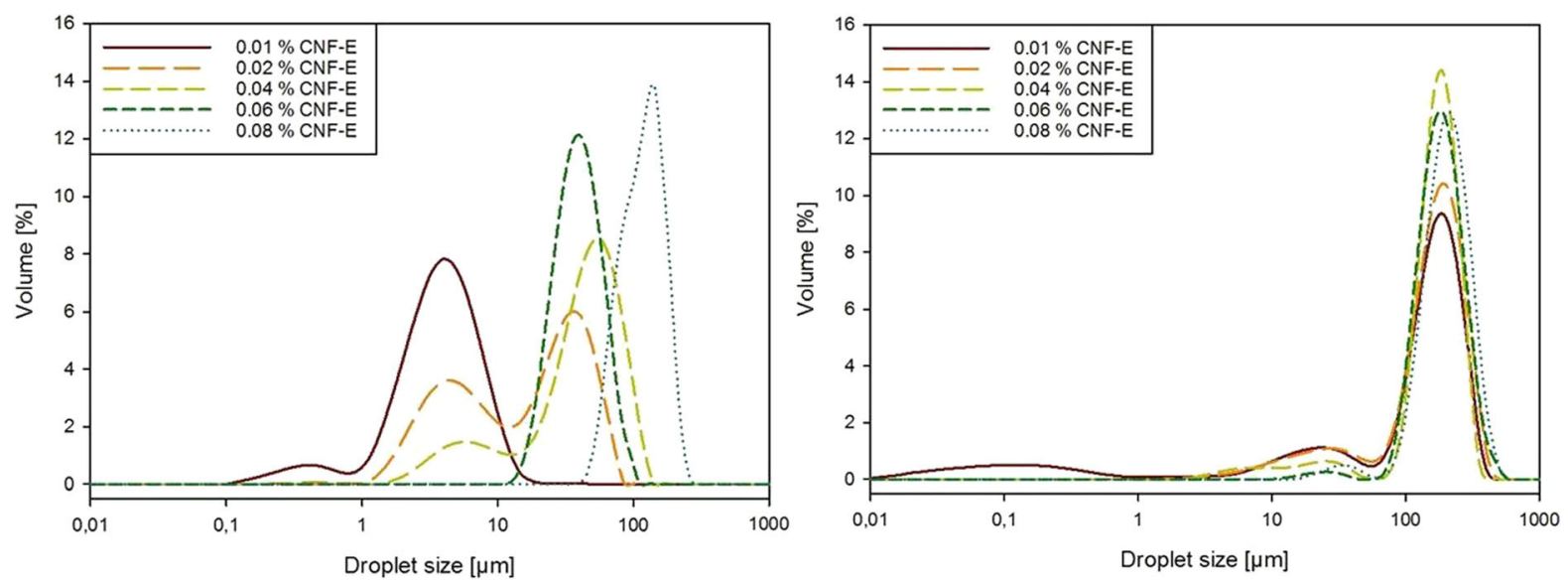

Fig. 5 Volume based droplet size distribution of emulsions stabilized with various concentrations of CNF-E, from a right after preparation and $\mathbf{b}$ after one month of storage at room temperature

micrographs, larger for CNF-E stabilized emulsions compared to CNF-T stabilized emulsions. The emulsion containing $0.01 \mathrm{wt} \% \mathrm{CNF}-\mathrm{E}$ and $5 \mathrm{wt} \%$ oil had Sauter diameter $2.18 \pm 0.08 \mu \mathrm{m}$ right after emulsification, while for the $0.08 \mathrm{wt} \% \mathrm{CNF}-\mathrm{E}$ and $40 \mathrm{wt} \%$ oil emulsion the dimeter was $120 \pm 30 \mu \mathrm{m}$. All the CNFE stabilized emulsions experienced a large increase in droplet sizes during the first week of storage, with very few small droplets remaining in the emulsions after 1 month of storage (Fig. 5b).

For these emulsions with low CNF concentrations, a high surface charge density of the CNFs, and a low oil content appears to be beneficial for obtaining a small average droplet size, and a good storage stability. The difference between the two CNF samples can stem both from the improved electrostatic repulsion of the CNF-T compared to CNF-E, and the coarseness of the material. The low CNFs/oil ratio favors finely fibrillated CNFs, as the mass can be more evenly distributed in the emulsion, compared to the coarser CNFs, making it possible to cover more oil surfaces.

Characterization of emulsions stabilized with CNF-T and GGM

Based on the results obtained for emulsion stabilization with CNFs, and with GGM (Mikkonen et al. 2016a, b; Mikkonen et al. 2009), emulsions of $5 \mathrm{wt} \%$ oil content, stabilized with either CNF-T $(0.01,0.04$ or $0.08 \mathrm{wt} \%)$, GGM ( 0.5 or $1.0 \mathrm{wt} \%)$ or combinations of these were prepared. The droplet size distribution of the emulsions measured by laser light scattering was followed from right after preparation and up to one month of storage.

The pictures in Fig. 6 show a denser packed emulsion layer on top of the emulsions stabilized with CNF-T, while no creaming is visible for the emulsions stabilized solely with GGM. For the emulsions stabilized with combinations of CNF-T and GGM, no creaming is visible. According to the Stokes equation, this can be due to either higher viscosity in the continuous phase, or to smaller droplets in the GGM emulsions. While no viscosity measurements were performed in this study, a $1 \mathrm{wt} \%$ GGM sample isolated by use of PHWE was measured to have a low viscosity of $1.0 \mathrm{mPa} \bullet \mathrm{s}$ at $100 \mathrm{~s}^{-1}$ in another study (Mikkonen et al. 2016a, b). In comparison, a $0.11 \mathrm{wt} \%$ TEMPO-oxidized CNF sample with charge density of $1068 \pm 61 \mu \mathrm{mol} / \mathrm{g}$, had a viscosity of about $20 \mathrm{mPa} \bullet \mathrm{s}$ at $100 \mathrm{~s}^{-1}$ (Aaen et al. 2019a, 2019b). The reason for the absence of creaming in the GGM and GGM + CNF stabilized emulsions is thus probably due to the smaller droplet sizes compared to the CNF stabilized emulsions, rather than a high viscosity in the continuous phase.

The microscopy images show a small decrease in droplet size with increasing CNF content (Fig. 7, top), when the oil content is kept constant at $5 \mathrm{wt} \%$. In addition, there is a shift in flocculation state between 0.04 wt \% CNF-T and 0.08 wt \% CNF-T, with large flocculates present for the higher $\mathrm{CNF}$ concentration. 


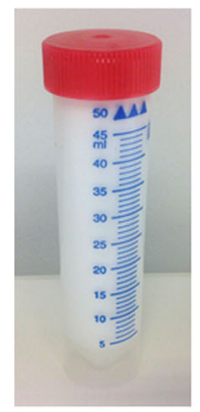

$0.01 \%$ CNF-T

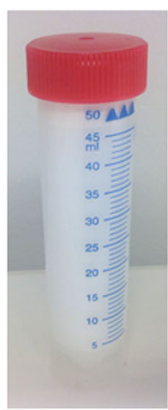

$0.04 \%$ CNF-T

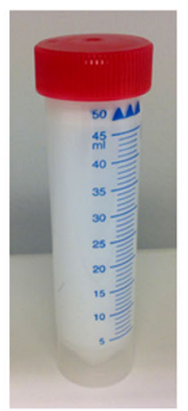

$0.08 \%$ CNF-T

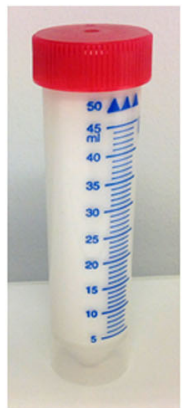

$0.5 \%$ GGM

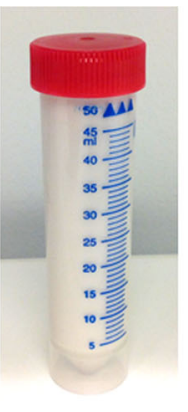

$1 \%$ GGM

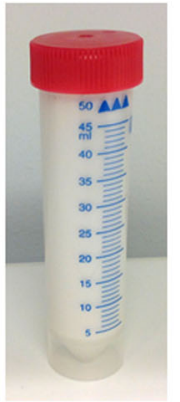

$0.01 \%$ CNF-T

$+0.5 \%$ GGM

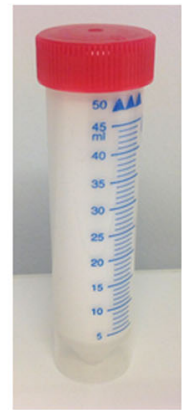

$0.04 \%$ CNF-T

$+0.5 \%$ GGM

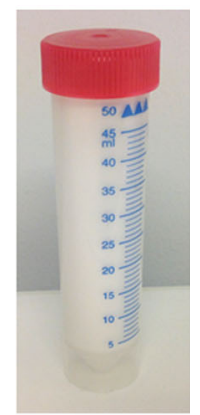

$0.08 \%$ CNF-T

$+0.5 \%$ GGM

Fig. 6 Pictures of $5 \mathrm{wt} \%$ oil emulsions stabilized with CNF-T, GGM or a combination of both, after 1 month of storage at room temperature. The ratio between oil content and CNFs is kept constant between the samples

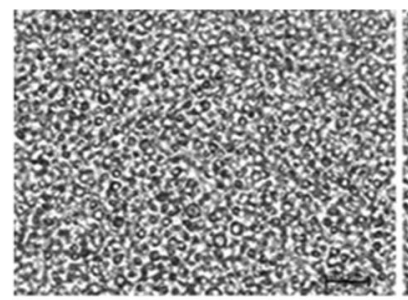

$0.01 \% \mathrm{CNF}-\mathrm{T}$

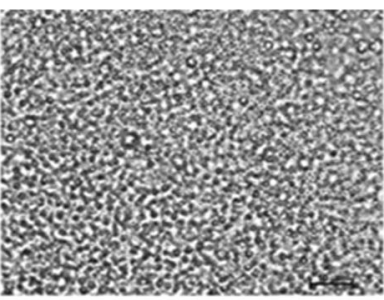

$0.04 \%$ CNF-T

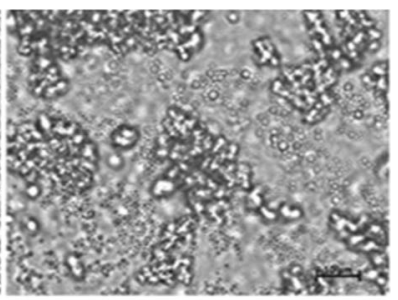

$0.08 \%$ CNF-T

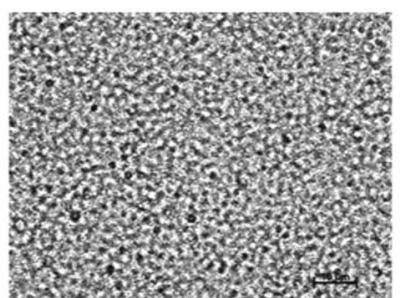

$0.5 \% \mathrm{GGM}$

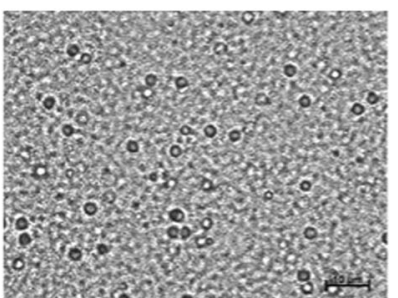

$1 \% \mathrm{GGM}$

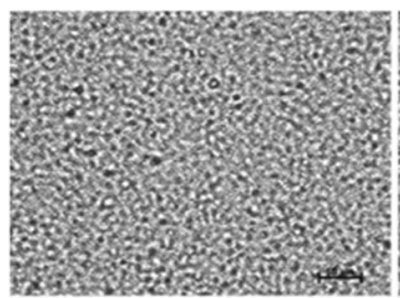

$0.01 \% \mathrm{CNF}-\mathrm{T}$

$+0.5 \%$ GGM

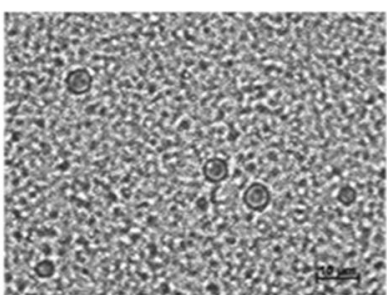

$0.04 \%$ CNF-T

$+0.5 \%$ GGM

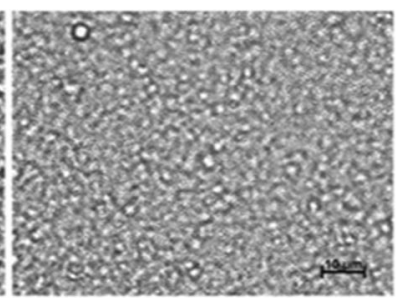

$0.08 \% \mathrm{CNF}-\mathrm{T}$

$+0.5 \% \mathrm{GGM}$
Fig. 7 Pictures from optical microscopy of emulsions containing $5 \mathrm{wt} \%$ rapeseed oil, stabilized with $0.01,0.04$ or $0.08 \mathrm{wt} \%$ CNF-T (top), 0.5 or 1 wt \% GGM (middle) or with combinations

As for the emulsions with the highest CNFs and oil content in the first part of the study (Fig. 3), the $0.08 \mathrm{CNF}-\mathrm{T}(5)$ differs from the rest of the emulsions, with a higher flocculation state, both for $5 \%$ and for of CNF-T and 0.5 wt \% GGM (bottom). The pictures are from the same day as emulsion preparation, with a scale bar of $10 \mu \mathrm{m}$ for all emulsions. Scale bar represents $10 \mu \mathrm{m}$

$40 \%$ oil. This implies that the CNF concentrations determining for the flocculation state between droplets, with more flocculation with higher CNF concentration, possibly due to some local network 
formation. Increasing the oil content can however also have an effect, as this leads to an increased effective $\mathrm{CNF}$ concentration in the aqueous phase. Flocculation is also observed in the 0.06CNF-T sample with $30 \mathrm{wt}$ $\%$ oil (Figure S1), where the effective CNF concentration in the aqueous phase is about the same as in the 0.08CNF-T(5) sample.

The emulsions stabilized with GGM (Fig. 7, middle) both have very small droplets. The $1 \%$ GGM emulsion seems to have many even smaller droplets than the one with $0.5 \%$ GGM, but also some larger droplets. For the emulsions stabilized with combinations of GGM and CNF-T (Fig. 7, bottom) the observed droplets are very small, with no major observable differences between the CNF concentrations. There may be some more flocculates present for the highest CNF-T concentration, but it is apparent that the GGM reduces the flocculation tendency for the CNF. As the flocculation requires the CNFs on the oil droplets to be in contact with each other, the introduction of GGM or an increased number of oil droplets, posing a steric hindrance between fibrils, may slow down the flocculation. The reason for the domination of GGM compared to CNF-T on droplet size could, in addition to the much higher concentration of GGM compared to CNFs, be that GGM, with its phenolic residues from lignin (Lahtinen et al. 2019; Lehtonen et al. 2018), has a higher affinity to the oil/ water interfaces than the CNFs.

The droplets size distributions (Fig. 8, top) show stable emulsions with a small decrease in volume droplet size for increasing CNF-T, which is also the case for the Sauter diameter, shown in Figure S4 in supplementary material. For the GGM stabilized emulsions (Fig. 8, bottom), the droplet size distribution is shifted towards smaller droplets for higher GGM content (average values for $\mathrm{D}_{3 ; 2}$ and $\mathrm{D}_{4 ; 3}$ are shown in Figure S5). This is in agreement with the results obtained by Bhattarai et al. (2018), where it was observed an increase in Sauter diameter and polydispersity with a decrease in GGM:oil ratio. They proposed incomplete saturation of newly formed surfaces as a possible cause for this, with increased coalescence resulting from collisions during homogenization (Bhattarai et al. 2018). As in their work, a bimodal distribution was obtained for the GGM stabilized emulsions. This was less evident in the emulsions where CNF-T was present together with the GGM, with a smaller population of larger droplets. By the look of the droplet size distributions, the GGM, with its much higher concentration, is the main factor determining the droplet size of the emulsions, with no significant contribution of CNFs on the average droplet size (Figure S5), as was observed from the micrographs.

The droplet size distributions after 1 month of storage indicates some coalescence of oil droplets or Ostwald ripening (where large droplets grow at the expense of small droplets due to solubility differences). The CNF-T, especially at $0.04 \mathrm{wt} \%$, appear to delay this process in the emulsion. An increase in viscosity in the continuous phase could result in this effect, but as the CNF concentration is very low, a more likely explanation may be some steric hindrance from surface adsorption of CNFs to the droplets. The flocculation tendency of the $0.08 \mathrm{wt} \% \mathrm{CNFs}$, can be a possible explanation why a slightly lower concentration of $0.04 \mathrm{wt} \%$ is more effective in delaying the increase in droplet size during storage.

\section{Oxidative stability of CNF-T- and GGM-stabilized} emulsions

Oxidative stability of highly unsaturated rapeseed oil was investigated during accelerated storage test at $40{ }^{\circ} \mathrm{C}$. Formation of volatile secondary oxidation products of lipids was monitored during four weeks of storage. Naturally occurring antioxidants were removed from the oil prior to emulsion preparation. This allowed us to study the influence of stabilizers on the emulsion stability without any interactions with the antioxidants.

Oxidation of unsaturated lipids was evident in CNF-T stabilized emulsion after two days of storage at $40{ }^{\circ} \mathrm{C}$ : Significant formation of hexanal (Fig. 9), 2-pentenal 2-heptenal and 2-octenal was detected (Figure S6-S8). Their formation was increasing the first few days, after which decomposition of these compounds dominated and, thus, a decrease in their contents was detected. At the same time, formation of further reaction products, hexanoic acid (Fig. 10) and octanoic acid (Figure S9), was increasing. Oxidation of both linolenic, linoleic and oleic acids was evident based on the formed products. For example, 2-pentenal is a typical oxidation product of linolenic acid, while hexanal and 2-heptenal represent the oxidation of linoleic acid and nonanal the oxidation of oleic acid 

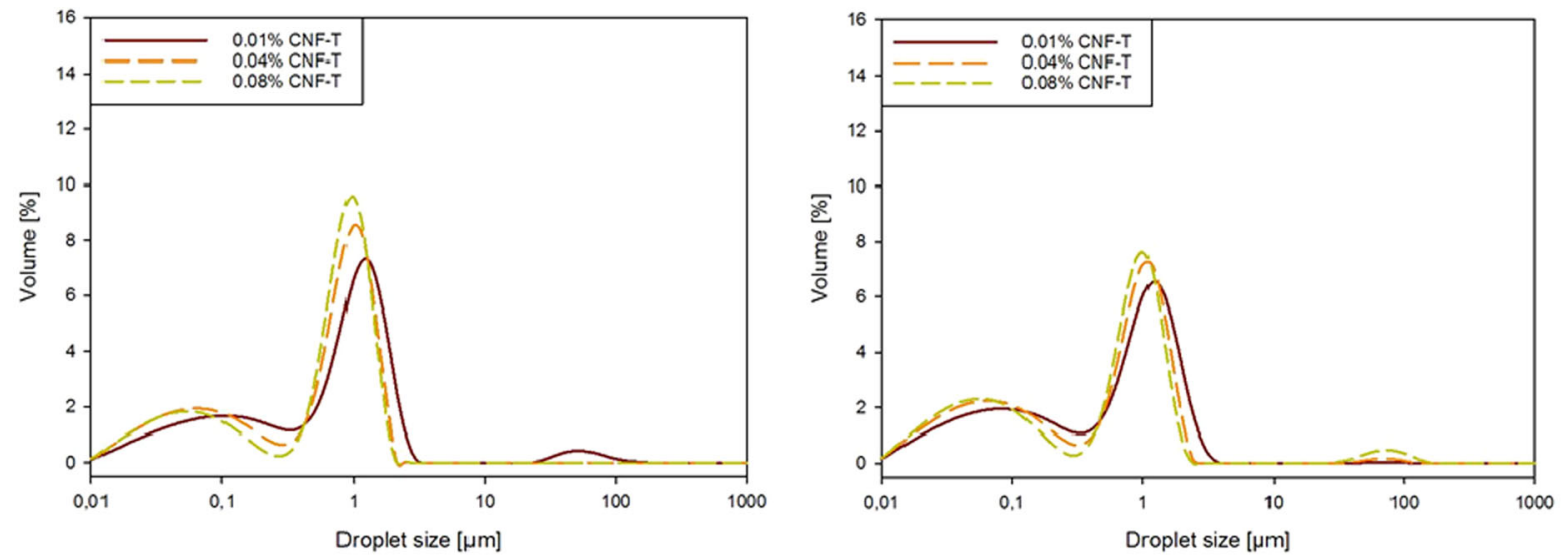

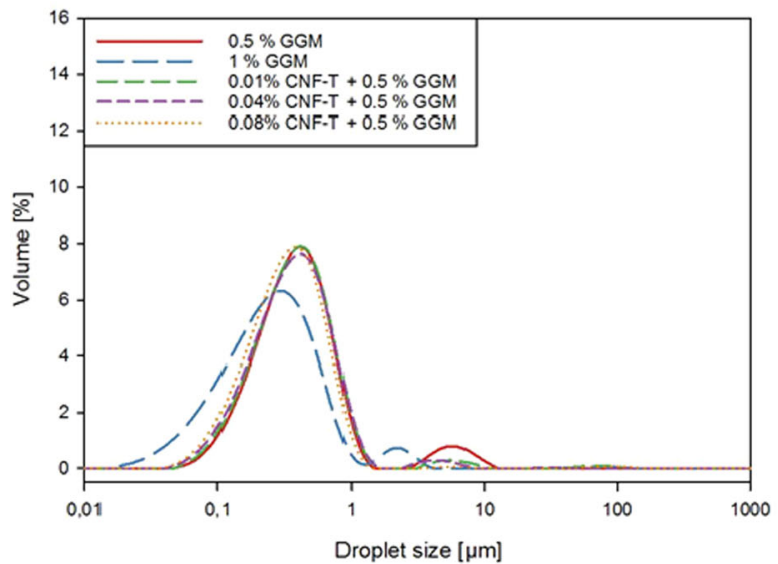

(a) Right after preparation

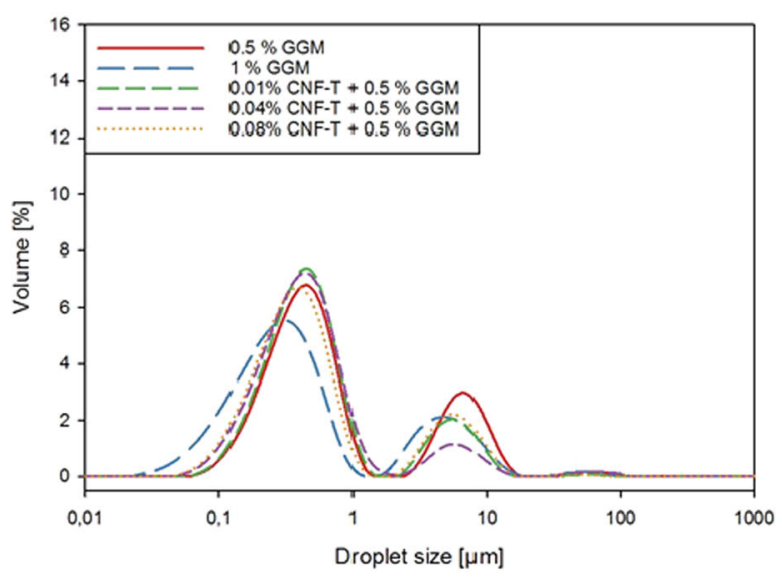

(b) After 1 month

Fig. 8 Droplet size distribution of emulsions stabilized with various concentrations of CNF-T (top) and combinations of GGM/CNF-T (bottom), from a) right after preparation and b) after one month of storage at room temperature

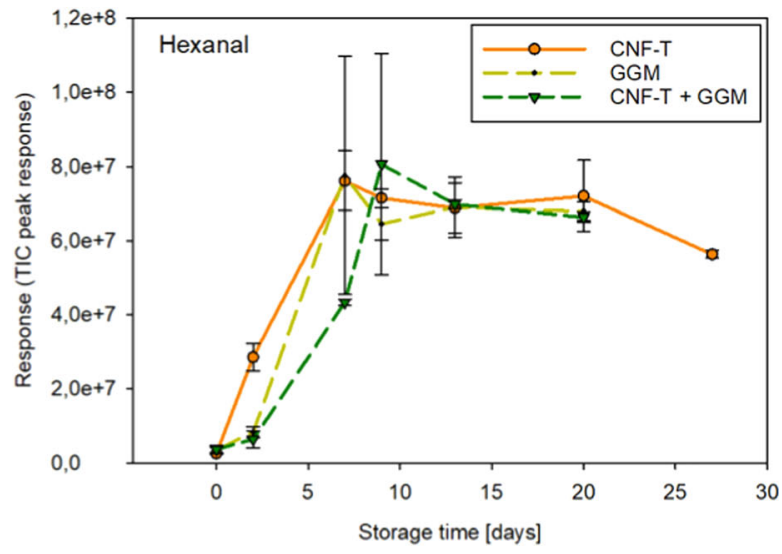

Fig. 9 Formation of the volatile secondary oxidation product Hexanal in CNF-T and GGM-stabilized emulsions during 27-day accelerated storage test at $40{ }^{\circ} \mathrm{C}$. The experiment was carried out at two different times, shown in two different graphs.

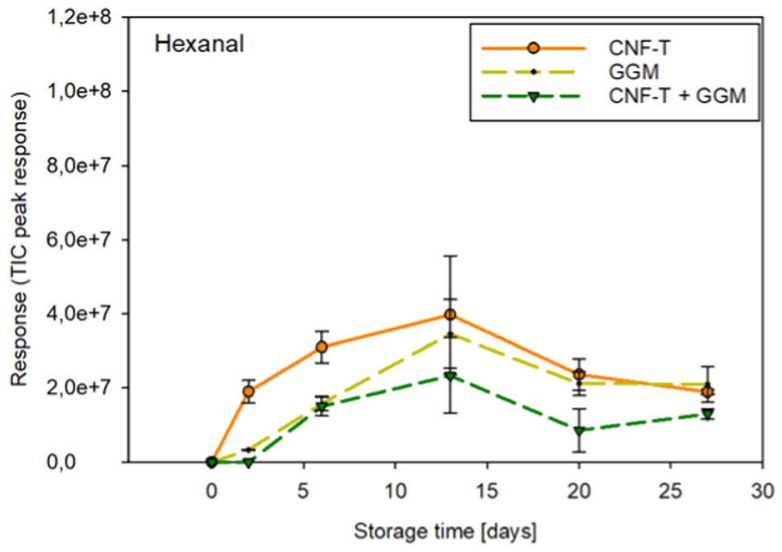

In each experiment, 3 individual vials containing the same emulsion were stored and analyzed, giving the average values and standard deviations shown in the graphs 


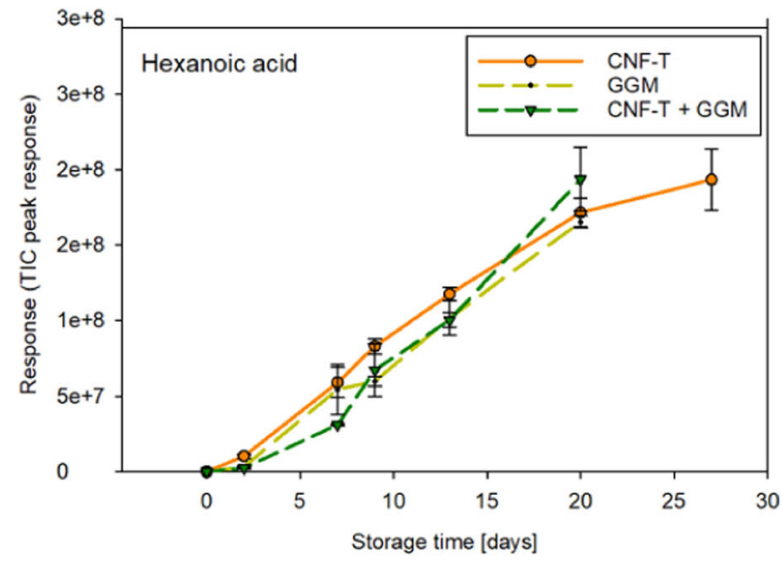

Fig. 10 Formation of the volatile secondary oxidation product hexanoic acid in CNF-T and GGM-stabilized emulsions during 27-day accelerated storage test at $40{ }^{\circ} \mathrm{C}$. The experiment was carried out at two different times, shown in two different graphs.

(Schaich 2013). These findings indicate that the oxidation was advanced.

Oxidation of lipids in emulsions stabilized by ethanol precipitated GGM progressed somewhat slower than in CNF-T-stabilized emulsions. After two days of storage, very low contents of oxidation indicators were detected. Their contents were however significant after 4-7 days, and even though a delay in the initiation of lipid oxidation was observed in the GGM-emulsion, the rate of oxidation was more or less similar as in the CNF-T-stabilized emulsion. The GGM used in this study contained lignin residues, which are hypothesized to act as antioxidants and delay oxidation by providing protection against radical mediated lipid oxidation (Lehtonen et al. 2016, 2018; Lahtinen et al. 2019).

Emulsion, which was stabilized by a mixture of CNF-T and GGM, behaved approximately as GGMstabilized emulsions. Initiation of lipid oxidation was delayed but after the radical formation was evident, the rate of oxidation was elevated, and the levels of formed oxidation products were similar as in the GGM-stabilized emulsions.

These results show that combining GGM in CNFT-stabilized emulsions provides some protection against lipid oxidation by delaying the initiation of oxidation reactions. These observed effects may be due the radical entrapping properties of GGM (Ebrigerová et al. 2008). These effects would be more

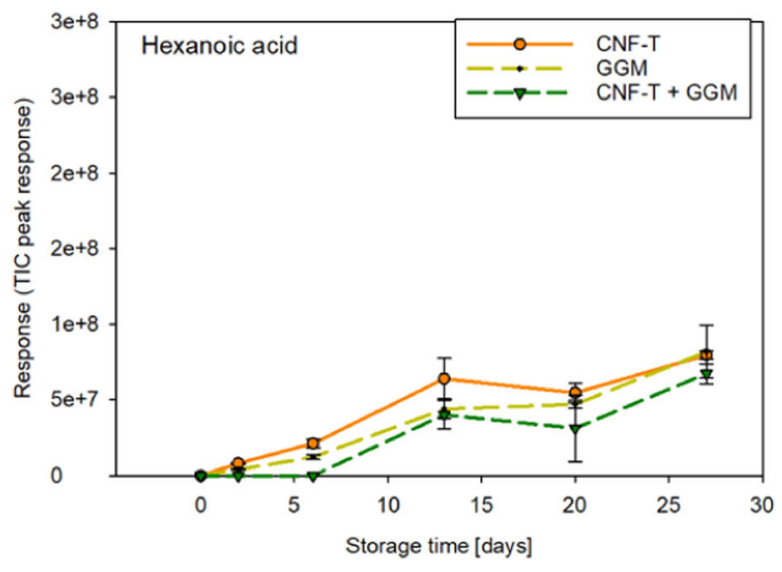

In each experiment, 3 individual vials containing the same emulsion were stored and analyzed, giving the average values and standard deviations shown in the graphs

pronounced in native GGM extracts, without the ethanol precipitation (Lehtonen et al. 2019).

\section{Conclusions}

Oil-in-water Pickering emulsions with various amounts of CNFs and rapeseed oil were prepared through stabilization with two different qualities of CNFs. GGM, with its previously shown protection against oxidative stability, was used in combinations with CNFs to stabilize 5 wt \% oil dilute emulsions. Droplet size distributions, micrographs and visual appearance were used to assess the physical stability of the emulsions over 1 month of storage at room temperature, while the formation of volatile secondary oxidation products was followed to study the oxidative stability. Emulsions where the CNF:oil ratio was kept constant showed large differences in droplet morphology and emulsion stability between the two CNF qualities, with the most stable emulsions obtained for the emulsion containing 0.01 wt $\%$ highly charged CNF-T, and 5 wt $\%$ oil. Keeping the oil content constant at $5 \mathrm{wt} \%$, an increase in CNF-T or GGM concentration resulted in slightly smaller oil droplets, with good storage stability for all the emulsions. The Pickering CNF emulsions obtained droplet sizes acceptable for several food applications, while the incorporation of GGM gave small enough droplet 
sizes to be relevant for use in beverage emulsions. Emulsions stabilized with combinations of GGM (0.5 wt \%) and CNF-T (0.01 - 0.08 wt \%), attained emulsion characteristics most similar to the GGM stabilized emulsions, but with the CNFs contributing to a somewhat slower emulsion destabilization. GGM provided some protection against oxidation, by delaying the initiation of oxidation reactions, both alone and in combination with CNF-T. The CNFs and GGM showed great promise in emulsion stabilization even at low concentrations, with improved storage stability when used in combination.

Acknowledgments This work has been funded by two projects. First, by the Research Council of Norway through the NANO2021 project NanoVisc (Grant no. 245300), initiated and led by RISE PFI, and partly funded by the companies Borregaard, Stora Enso, Mercer and the foundation Papirindustriens Forskningsinstitutt. And secondly, by SNS Nordic Forest Research, through the project "Valorization of wood biorefinery products into novel functional hydrocolloids (WOOD-PRO)". Borregaard is much appreciated for their contribution with the Exilva CNFs. The authors would like to give special thanks to Mamata Bhattarai, Hongbo Zhao and the rest of the research group at the Department of Food and Nutrition, University of Helsinki, for all their help and guidance in the laboratory.

Author's contribution All authors contributed to the study conception and design. Material preparation, data collection and analysis were performed by RA and ML. The first draft of the manuscript was written by RA and ML, and all authors commented on previous versions of the manuscript. All authors read and approved the final manuscript.

Funding Open access funding provided by NTNU Norwegian University of Science and Technology (incl St. Olavs Hospital Trondheim University Hospital). This work has been funded by two projects. First, by the Research Council of Norway through the NANO2021 project NanoVisc (Grant no. 245300), initiated and led by RISE PFI, and partly funded by the companies Borregaard, Stora Enso, Mercer and the foundation Papirindustriens Forskningsinstitutt. And secondly, by SNS Nordic Forest Research, through the project "Valorization of wood biorefinery products into novel functional hydrocolloids (WOOD-PRO)".

\section{Declarations}

Conflict of interest The authors declared that there is no conflict of interest.

Open Access This article is licensed under a Creative Commons Attribution 4.0 International License, which permits use, sharing, adaptation, distribution and reproduction in any medium or format, as long as you give appropriate credit to the original author(s) and the source, provide a link to the Creative
Commons licence, and indicate if changes were made. The images or other third party material in this article are included in the article's Creative Commons licence, unless indicated otherwise in a credit line to the material. If material is not included in the article's Creative Commons licence and your intended use is not permitted by statutory regulation or exceeds the permitted use, you will need to obtain permission directly from the copyright holder. To view a copy of this licence, visit http://creativecommons.org/licenses/by/4.0/.

\section{References}

Aaen R, Brodin FW, Simon S, Heggset EB, Syverud K (2019a) Oil-in-Water emulsions stabilized by cellulose nanofibrils-The effects of ionic strength and $\mathrm{pH}$. Nanomaterials 9(2):259. https://doi.org/10.3390/nano9020259

Aaen R, Simon S, Brodin FW, Syverud K (2019b) The potential of TEMPO-oxidized cellulose nanofibrils as rheology modifiers in food systems. Cellulose 26(9):5483-5496. https://doi.org/10.1007/s10570-019-02448-3

Arslan-Alaton I, Erdinc E (2006) Effect of photochemical treatment on the biocompatibility of a commercial nonionic surfactant used in the textile industry. Water Res 40(18):3409-3418. https://doi.org/10.1016/j.watres.2006. 07.014

Aspinall GO (1959) Structural Chemistry of the Hemicelluloses. In M. L. Wolfrom (Ed.), Advances in Carbohydrate Chemistry (Vol. 14, pp. 429-468): Academic Press. https:// doi.org/10.1016/S0096-5332(08)60228-3

Aulin C, Johansson E, Wågberg L, Lindström T (2010) Selforganized films from cellulose I nanofibrils using the layerby-layer technique. Biomacromol 11(4):872-882. https:// doi.org/10.1021/bm100075e

Bhattarai M, Pitkänen L, Kitunen V, Korpinen R, Ilvesniemi H, Kilpeläinen PO, Lethonen M, Mikkonen KS (2018) Functionality of spruce galactoglucomannans in oil-inwater emulsions. Food Hydrocoll. https://doi.org/10.1016/ j.foodhyd.2018.03.020

Bhattarai M, Sulaeva I, Pitkänen L, Kontro I, Tenkanen M, Potthast A, Mikkonen KS (2020) Colloidal features of softwood galactoglucomannans-rich extract. Carbohydr Polym 241:116368. https://doi.org/10.1016/j.carbpol. 2020.116368

Binks BP (2002) Particles as surfactants-similarities and differences. Curr Opin Colloid Interface Sci 7(1-2):21-41. https://doi.org/10.1016/S1359-0294(02)00008-0

Capron I, Cathala B (2013) Surfactant-free high internal phase emulsions stabilized by cellulose nanocrystals. Biomacromol 14(2):291-296. https://doi.org/10.1021/ bm301871k

Carvalho DMD, Lahtinen MH, Lawoko M, Mikkonen KS (2020) Enrichment and identification of lignin-carbohydrate complexes in softwood extract. ACS Sustain. Chem. Eng. 8(31):11795-11804. https://doi.org/10.1021/ acssuschemeng.0c03988

Cunha AG, Mougel J-B, Cathala B, Berglund LA, Capron I (2014) Preparation of double pickering emulsions 
stabilized by chemically tailored nanocelluloses. Langmuir 30(31):9327-9335. https://doi.org/10.1021/la5017577

Fujisawa S, Togawa E, Kuroda K (2016) Facile route to transparent, strong, and thermally stable nanocellulose/polymer nanocomposites from an aqueous Pickering emulsion. Biomacromol 18(1):266-271. https://doi.org/10.1021/acs. biomac.6b01615

Fujisawa S, Togawa E, Kuroda K (2017) Nanocellulose-stabilized Pickering emulsions and their applications. Sci Technol Adv Mater 18(1):959-971. https://doi.org/10. 1080/14686996.2017.1401423

Gabrielii I, Gatenholm P, Glasser WG, Jain RK, Kenne L (2000) Separation, characterization and hydrogel-formation of hemicellulose from aspen wood. Carbohydr Polym 43(4):367-374. 8617(00)00181-8 https://doi.org/10.1016/S0144-

Gestranius M, Stenius P, Kontturi E, Sjöblom J, Tammelin T (2017) Phase behaviour and droplet size of oil-in-water Pickering emulsions stabilised with plant-derived nanocellulosic materials. Colloids Surf Physicochem Eng Asp 519:60-70. https://doi.org/10.1016/j.colsurfa.2016. 04.025

Gomez V, Ferreres L, Pocurull E, Borrull F (2011) Determination of non-ionic and anionic surfactants in environmental water matrices. Talanta 84(3):859-866. https://doi. org/10.1016/j.talanta.2011.02.009

Jardak K, Drogui P, Daghrir R (2016) Surfactants in aquatic and terrestrial environment: occurrence, behavior, and treatment processes. Environ Sci Pollut Res 23(4):3195-3216. https://doi.org/10.1007/s11356-015-5803-x

Kilpeläinen P, Hautala S, Byman O, Tanner L, Korpinen R, Lillandt MK, Pranovich AV, Kitunen VH, Willför SM, Ilvesniemi H (2014) Pressurized hot water flow-through extraction system scale up from the laboratory to the pilot scale. Green Chem 16(6):3186-3194. https://doi.org/10. 1039/C4GC00274A

Klemm D, Kramer F, Moritz S, Lindström T, Ankerfors M, Gray D, Dorris A (2011) Nanocelluloses: a new family of naturebased materials. Angew Chem Int Ed 50(24):5438-5466. https://doi.org/10.1002/anie.201001273

Lahtinen MH, Valoppi F, Juntti V, Heikkinen S, Kilpeläinen PO, Maina NH, Mikkonen KS (2019) Lignin-rich PHWE hemicellulose extracts responsible for extended emulsion stabilization. Front Chem. https://doi.org/10.3389/fchem. 2019.00871

Lehtonen M, Merinen M, Kilpeläinen PO, Xu C, Willför SM, Mikkonen KS (2018) Phenolic residues in spruce galactoglucomannans improve stabilization of oil-in-water emulsions. J Colloid Interface Sci 512:536-547. https:// doi.org/10.1016/j.jcis.2017.10.097

Lehtonen M, Teräslahti S, Xu C, Yadav MP, Lampi A-M, Mikkonen KS (2016) Spruce galactoglucomannans inhibit lipid oxidation in rapeseed oil-in-water emulsions. Food Hydrocoll 58:255-266. https://doi.org/10.1016/j.foodhyd. 2016.03.006

Leppänen K, Spetz P, Pranovich A, Hartonen K, Kitunen V, Ilvesniemi H (2011) Pressurized hot water extraction of Norway spruce hemicelluloses using a flow-through system. Wood Sci Technol 45(2):223-236. https://doi.org/10. 1007/s00226-010-0320-z
Liimatainen H, Visanko M, Sirviö JA, Hormi OE, Niinimaki J (2012) Enhancement of the nanofibrillation of wood cellulose through sequential periodate-chlorite oxidation. Biomacromol 13(5):1592-1597. https://doi.org/10.1021/ bm300319m

Lu Y, Qian X, Xie W, Zhang W, Huang J, Wu D (2019) Rheology of the sesame oil-in-water emulsions stabilized by cellulose nanofibers. Food Hydrocoll 94:114-127. https:// doi.org/10.1016/j.foodhyd.2019.03.001

Mcclements DJ (2007) Critical review of techniques and methodologies for characterization of emulsion stability. Crit Rev Food Sci Nutr 47(7):611-649. https://doi.org/10. 1080/10408390701289292

Mikkonen KS, Merger D, Kilpeläinen P, Murtomäki L, Schmidt US, Wilhelm M (2016a) Determination of physical emulsion stabilization mechanisms of wood hemicelluloses via rheological and interfacial characterization. Soft Matter 12(42):8690-8700. https://doi.org/10.1039/C6SM01557C

Mikkonen KS, Tenkanen M, Cooke P, Xu C, Rita H, Willför S, Holmbom B, Hicks KB, Yadav MP (2009) Mannans as stabilizers of oil-in-water beverage emulsions. LWT-Food Sci Technol 42(4):849-855. https://doi.org/10.1016/j.lwt. 2008.11.010

Mikkonen KS, Xu C, Berton-Carabin C, Schroën K (2016b) Spruce galactoglucomannans in rapeseed oil-in-water emulsions: efficient stabilization performance and structural partitioning. Food Hydrocoll 52:615-624. https://doi. org/10.1016/j.foodhyd.2015.08.009

Mikulcová V, Bordes R, Kašpárková V (2016) On the preparation and antibacterial activity of emulsions stabilized with nanocellulose particles. Food Hydrocoll 61:780-792. https://doi.org/10.1016/j.foodhyd.2016.06.031

Nechyporchuk O, Belgacem MN, Bras J (2016) Production of cellulose nanofibrils: A review of recent advances. Ind Crops Prod 93:2-25. https://doi.org/10.1016/j.indcrop. 2016.02.016

Pickering SU (1907a) CXCVI.-Emulsions. J. Chem. Soc., Perkin. Tran., 91(0), 2001-2021. doi:https://doi.org/10.1039/ CT9079102001

Pickering SU (1907b) Cxcvi.- emulsions. J Chem Soc Perkin Tran, 91, 2001-2021

Piorkowski DT, McClements DJ (2014) Beverage emulsions: recent developments in formulation, production, and applications. Food Hydrocoll 42:5-41. https://doi.org/10. 1016/j.foodhyd.2013.07.009

Pääkkö M, Ankerfors M, Kosonen H, Nykänen A, Ahola S, Österberg M, Ruokolainen J, Laine J, Larsson PT, Ikkala O, Lindström T (2007) Enzymatic hydrolysis combined with mechanical shearing and high-pressure homogenization for nanoscale cellulose fibrils and strong gels. Biomacromol 8(6):1934-1941. https://doi.org/10.1021/ bm061215p

Rowell, R. M. (2012). Handbook of wood chemistry and wood composites: CRC press

Saito T, Isogai A (2004) TEMPO-mediated oxidation of native cellulose. The effect of oxidation conditions on chemical and crystal structures of the water-insoluble fractions. Biomacromol 5(5):1983-1989

Saito T, Isogai A (2006) Introduction of aldehyde groups on surfaces of native cellulose fibers by TEMPO-mediated oxidation. Colloids Surf a Physicochem Eng Asp 
289(1):219-225. https://doi.org/10.1016/j.colsurfa.2006. 04.038

Saito T, Nishiyama Y, Putaux J-L, Vignon M, Isogai A (2006) Homogeneous suspensions of individualized microfibrils from TEMPO-catalyzed oxidation of native cellulose. Biomacromol 7(6):1687-1691. https://doi.org/10.1021/ bm060154s

Sjostrom E (1993) Wood chemistry: fundamentals and applications: Gulf professional publishing

Song T, Pranovich A, Sumerskiy I, Holmbom B (2008) Extraction of galactoglucomannan from spruce wood with pressurised hot water. Holzforschung 62(6):659-666

Tejado A, Alam MN, Antal M, Yang H, van de Ven TG (2012) Energy requirements for the disintegration of cellulose fibers into cellulose nanofibers. Cellulose 19(3):831-842. https://doi.org/10.1007/s10570-012-9694-4

Valoppi F, Lahtinen MH, Bhattarai M, Kirjoranta SJ, Juntti VK, Peltonen LJ, Kilpeläinen PO, Mikkonen KS (2019) Centrifugal fractionation of softwood extracts improves the biorefinery workflow and yields functional emulsifiers. Green Chem 21(17):4691-4705. https://doi.org/10.1039/ C9GC02007A

Walstra P (2002) Physical chemistry of foods. CRC Press, USA

Whitehurst RJ (2004) Emulsifiers in food technology. Wiley, New York
Winuprasith T, Suphantharika M (2015) Properties and stability of oil-in-water emulsions stabilized by microfibrillated cellulose from mangosteen rind. Food Hydrocoll 43:690-699. https://doi.org/10.1016/j.foodhyd.2014.07. 027

Wågberg L, Decher G, Norgren M, Lindström T, Ankerfors M, Axnäs K (2008) The build-up of polyelectrolyte multilayers of microfibrillated cellulose and cationic polyelectrolytes. Langmuir 24(3):784-795. https://doi.org/10.1021/ la702481v

Xhanari K, Syverud K, Chinga-Carrasco G, Paso K, Stenius P (2011a) Structure of nanofibrillated cellulose layers at the o/w interface. J Colloid Interface Sci 356(1):58-62. https:// doi.org/10.1016/j.jcis.2010.12.083

Xhanari K, Syverud K, Stenius P (2011b) Emulsions stabilized by microfibrillated cellulose: the effect of hydrophobization, concentration and o/w ratio. J Dispers Sci Technol 32(3):447-452. https://doi.org/10.1080/ 01932691003658942

Publisher's Note Springer Nature remains neutral with regard to jurisdictional claims in published maps and institutional affiliations. 